\title{
DERMATOPHYTOSIS IN AND AROUND MAHABUBNAGAR
}

Anusandanam Pavani ${ }^{1}$, Manisha Singh ${ }^{2}$, Sreekanth Basireddy33, Vasanti Kabra ${ }^{4}$

${ }^{1}$ Scientist, Palamur Bio-Sciences, Mahabubnagar.

2Professor, Department of Microbiology, SVS Medical College, Mahabubnagar.

${ }^{3}$ Assistant Professor, Department of Microbiology, Kurnool Medical College, Kurnool.

${ }^{4}$ Professor and HOD, Department of Microbiology, SVS Medical College, Mahabubnagar.

\section{ABSTRACT}

Dermatophytes are one of the most common fungal agents causing superficial skin infections. The prevalence of these infections varies from place to place and is more commonly associated with poor socioeconomic status.

\section{AIMS AND OBJECTIVES}

The study aims to know prevalence of dermatophytosis and its distribution patterns among clinical specimens in and around Mahabubnagar.

\section{MATERIALS AND METHODS}

Skin, hair and nail samples were collected from all the clinically suspected cases attending the Dermatology OPD from Aug 2013 - July 2014. Samples were examined microscopically under KOH mount. Culture was done on Sabouraud dextrose agar with antibiotics and Dermatophytes test medium and isolates were identified based on the cultural, microscopic and biochemical characteristics.

\section{RESULTS}

Out of 88 specimens obtained, 58 (65.9\%) were $\mathrm{KOH}$ positive and $30(34 \%)$ were $\mathrm{KOH}$ negative. Culture positivity was seen in $59(67 \%)$ samples. Tinea corporis was the most common clinical presentation $32(36 \%)$ followed by Tinea cruris $20(22.7 \%)$. Trichophyton mentagrophytes was the most common species isolated 41 (69.5\%) followed by Trichophyton rubrum 9 (15.25\%).

\section{CONCLUSION}

Trichophyton mentagrophytes was identified as the principal aetiological agent in our hospital, predominately presenting with clinical presentation of Tinea corporis.

\section{KEYWORDS}

Dermatophytes, T. corporis, T. mentagrophytes, DTM Medium.

HOW TO CITE THIS ARTICLE: Pavani A, Singh M, Basireddy S, et al. Dermatophytosis in and around Mahabubnagar. J. Evolution Med. Dent. Sci. 2016;5(32):1739-1743, DOI: 10.14260/jemds/2016/410

\section{INTRODUCTION}

Dermatophytosis refers to superficial fungal infection of keratinized tissues caused by dermatophytes. They are a group of closely related fungi that which invade keratinized tissues like skin, hair and nails to produce an infection known as dermatophytosis. ${ }^{1}$

Dermatophytosis is commonly referred to as ringworm or tinea infections. Infection is restricted to the non-living layers of the skin because of the inability of the fungi to penetrate the deeper tissues. Many different species of dermatophytes under the genera Epidermophyton, Microsporum and Trichophyton are implicated in the causation of dermatophytosis. ${ }^{2}$

Dermatophytosis is one of the most common fungal infections seen throughout the world. In tropical and subtropical countries, it occurs in increasing frequencies. The local aetiological pattern of fungal isolates from clinical specimens may vary with time and geographical area and it is important to be familiar with recent local trends in order to improve diagnosis.

Financial or Other, Competing Interest: None.

Submission 04-03-2016, Peer Review 31-03-2016,

Acceptance 05-04-2016, Published 21-04-2016.

Corresponding Author:

Dr. Manisha Singh,

Professor, Department of Microbiology,

SVS Medical College,

Mahabubnagar.

E-mail: drsinghmanisha@gmail.com

DOI: $10.14260 /$ jemds/2016/410
Identification of fungal agent and species responsible for dermatophytosis is of importance not only for the epidemiology, but also for therapeutic point of view when treatment is advised for prolonged periods. Hot and humid climate of India predisposes to dermatophytic infection of skin. ${ }^{3}$ Different studies have been conducted in different parts of the country including Tamilnadu 4 , Madhya Pradesh 5 , Andhra Pradesh6,7, Karnataka ${ }^{8}$ and few other states. The distribution, frequency and the causative agents involved varied from study to study and from place to place depending upon various factors like climatic, socioeconomic conditions and the population density of that particular area for which the present study has been taken in order to know the local distribution patterns of the aetiological agents in our place.

\section{AIMS AND OBJECTIVES}

1. To study the prevalence of dermatophytosis and its distribution patterns among clinical specimens in and around Mahabubnagar.

2. To isolate and identify the aetiological agents up to the species level.

\section{MATERIALS AND METHODS}

A prospective study was conducted on patients diagnosed clinically as having dermatophytosis in the Outpatient Department of Dermatology from August 2013 to July 2014. A detailed clinical history was elicited from all the patients. Skin, hair and nail samples were collected from all the affected sites under aseptic precautions. 
All the samples were examined microscopically under KOH wet mount (10\% for skin, hair and $20 \%$ for nail). All the samples (skin scrape, nail clipping and hair clippings) were inoculated directly onto the Sabouraud Dextrose Agar (SDA) containing chloramphenicol (HiMedia MM1067, Lot No. 0000216421) and cycloheximide by pressing the specimen lightly into the surface of the agar. Simultaneously, they were also inoculated on the Dermatophyte Test Medium (DTM) (HiMedia M188, Lot No. 0000143240). These inoculated cultures were incubated at $25^{\circ} \mathrm{C}$ for 4 weeks. The culture isolates were identified based on the growth characteristics and microscopic morphology of the conidia (Micro and Macroconidia) in Lactophenol Cotton Blue (LPCB) Mount. Supplementary tests like Urease test, Hair perforation test were also done when necessary. 9,10

\section{RESULTS}

A total of 88 specimens obtained during the period of one year were processed by $\mathrm{KOH}$ examination and culture. Among these 88 samples, 58 (65.9\%) were $\mathrm{KOH}$ positive and 30 (34\%) were $\mathrm{KOH}$ negative.

In these $58 \mathrm{KOH}$ positive samples, 49 (55.68\%) were culture positive and the remaining $9(10.22 \%)$ isolates were culture negative. In the remaining $30(34.09 \%) \mathrm{KOH}$ negative samples, 10 (11.36\%) were culture positive and 20 (22.72\%) were culture negative. In our study, the total culture positivity was slightly higher $59(67.04 \%)$ than the total $\mathrm{KOH}$ positivity $58(65.90 \%)$.
Maximum cases were seen in the age group of 21-40 years 43 (48.9\%) followed by $41-60$ years 23 (26.1\%), only 2 cases were above the age of 60 years. Males were more affected $68(76.86 \%)$ than females $20(26.13 \%)$ with male-tofemale ratio of 2.82:1.

\begin{tabular}{|c|c|c|c|}
\hline Sl. No. & Clinical Types & No. of Cases & Percentage \\
\hline 1 & Tinea corporis & 32 & $36.4 \%$ \\
\hline 2 & Tinea cruris & 20 & $22.7 \%$ \\
\hline 3 & Tinea capitis & 8 & $9.1 \%$ \\
\hline 4 & Tinea pedis & 5 & $5.7 \%$ \\
\hline 5 & Tinea unguium & 4 & $4.5 \%$ \\
\hline 6 & Tinea faciei & 3 & $3.4 \%$ \\
\hline 7 & Tinea barbae & 1 & $1.1 \%$ \\
\hline 8 & Multiple sites & 15 & $17 \%$ \\
\hline \multicolumn{2}{|c|}{ Table 2: Clinical Analysis of Cases of Dermatophytes } \\
\hline
\end{tabular}

In our study Tinea corporis was the most common clinical presentation 32 (36.4\%) followed by Tinea cruris 20 (22.7\%), Tinea capitis $8(9.1 \%)$ and Tinea pedis $5(5.7 \%)$ Other sites like Tinea unguium 4 (4.7\%), Tinea faciei $3(3.4 \%)$ and Tinea barbae $1(1.1 \%)$ together accounted for less than $10 \%$ of total specimens.

Specimens were also obtained from multiple sites contributing to significant percentage 15 (17.04\%) among the total specimens. In these clinical types, majority were obtained in the combined sites of Tinea corporis and Tinea cruris $10(11.36 \%)$.

\begin{tabular}{|c|c|c|c|}
\hline & $\begin{array}{c}\text { KOH Positive } \\
\text { n (\%) }\end{array}$ & $\begin{array}{c}\text { KOH Negative } \\
\text { n (\%) }\end{array}$ & $\begin{array}{c}\text { Total } \\
\text { n (\%) }\end{array}$ \\
\hline Culture Positive & $49(55.7 \%)$ & $10(11.4 \%)$ & $59(67 \%)$ \\
\hline Culture Negative & $9(10.2 \%)$ & $20(22.7 \%)$ & $29(33 \%)$ \\
\hline Total & $\mathbf{5 8}(\mathbf{6 5 . 9 \% )}$ & $\mathbf{3 0}(\mathbf{3 4 . 1 \% )}$ & $\mathbf{8 8}(100 \%)$ \\
\hline \multicolumn{2}{|r}{}
\end{tabular}

\begin{tabular}{|c|c|c|c|c|c|c|}
\hline Sl. No. & Lesions & $\begin{array}{l}\text { Total } \\
\text { Cases }\end{array}$ & $\begin{array}{l}\text { Microscopy and } \\
\text { Culture Positive }\end{array}$ & $\begin{array}{l}\text { Microscopy and } \\
\text { Culture Negative }\end{array}$ & $\begin{array}{c}\text { Microscopy } \\
\text { Negative and } \\
\text { Culture Positive }\end{array}$ & $\begin{array}{c}\text { Microscopy } \\
\text { and Culture } \\
\text { Negative }\end{array}$ \\
\hline 1 & Tinea corporis & 32 & 16 & 4 & 1 & 11 \\
\hline 2 & Tinea cruris & 20 & 14 & 2 & 2 & 2 \\
\hline 3 & Tinea capitis & 8 & 2 & 1 & 2 & 3 \\
\hline 4 & Tinea pedis & 5 & 4 & - & 1 & - \\
\hline 5 & Tinea unguium & 4 & - & 1 & - & 3 \\
\hline 6 & Tinea faciei & 3 & 1 & - & 1 & 1 \\
\hline 7 & Tinea barbae & 1 & - & - & 1 & - \\
\hline 8 & Multiple sites & 15 & 12 & 1 & 2 & - \\
\hline Total & & 88 & $49(55.68 \%)$ & $9(10.22 \%)$ & $10(11.36 \%)$ & $20(22.72 \%)$ \\
\hline \multicolumn{7}{|c|}{ Table 3: Analysis of Mycological Confirmed Cases } \\
\hline
\end{tabular}

\begin{tabular}{|c|c|c|c|c|c|c|c|}
\hline $\begin{array}{c}\text { Clinical } \\
\text { Type }\end{array}$ & $\begin{array}{c}\text { T. } \\
\text { mentagrophytes }\end{array}$ & $\begin{array}{c}\text { T. } \\
\text { rubrum }\end{array}$ & $\begin{array}{c}\text { T. } \\
\text { tonsurans }\end{array}$ & $\begin{array}{c}\text { T. } \\
\text { verrucosum }\end{array}$ & $\begin{array}{c}\text { M. } \\
\text { canis }\end{array}$ & $\begin{array}{c}\text { E. } \\
\text { floccosum }\end{array}$ & $\begin{array}{c}\text { Total } \\
\text { Isolates }\end{array}$ \\
\hline T. corporis & 12 & 3 & - & - & 2 & - & 17 \\
\hline T. cruris & 9 & 4 & - & - & 2 & 1 & 16 \\
\hline T. capitis & 1 & - & 2 & - & - & - & 4 \\
\hline T. pedis & 3 & 1 & - & - & 1 & - & 5 \\
\hline T. faciei & 2 & - & - & - & - & - & 2 \\
\hline T. barbae & 1 & - & - & - & - & - & 1 \\
\hline $\begin{array}{c}\text { Multiple } \\
\text { sites }\end{array}$ & 13 & 1 & - & - & - & - & 14 \\
\hline Total & $\mathbf{4 1 ( 6 9 . 5 \% )}$ & $\begin{array}{c}\mathbf{9} \\
(15.25 \%)\end{array}$ & $\mathbf{2}(3.4 \%)$ & $\mathbf{1}(1.69 \%)$ & $\mathbf{5}$ & $\mathbf{1}(1.69 \%)$ & $\mathbf{5 9}$ \\
\hline \multicolumn{7}{|c|}{ Table 4: Lesion Wise Distribution of Isolates } \\
\hline
\end{tabular}




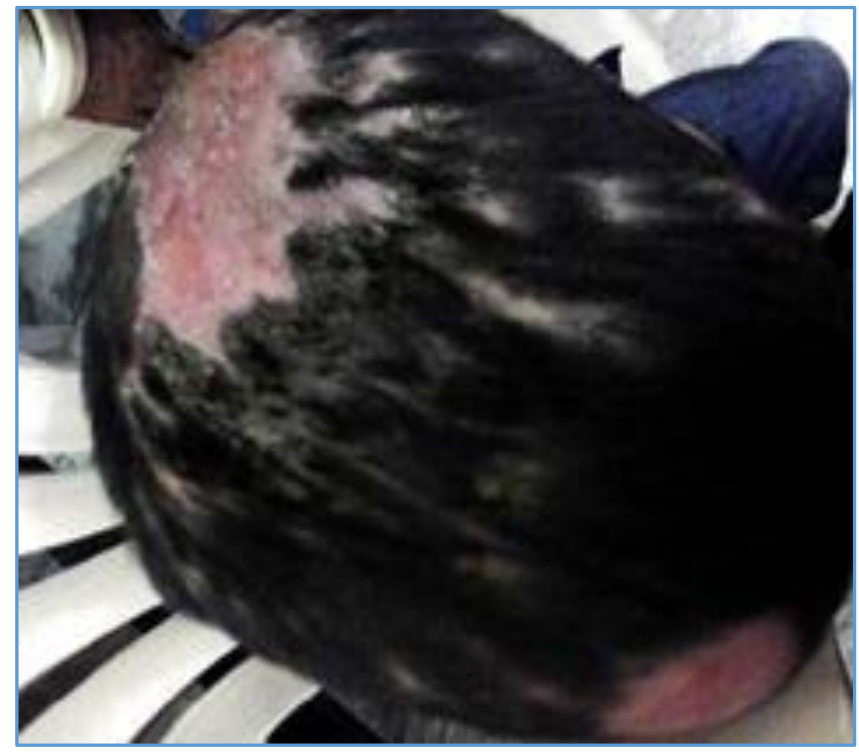

Fig. 1: T. capitis

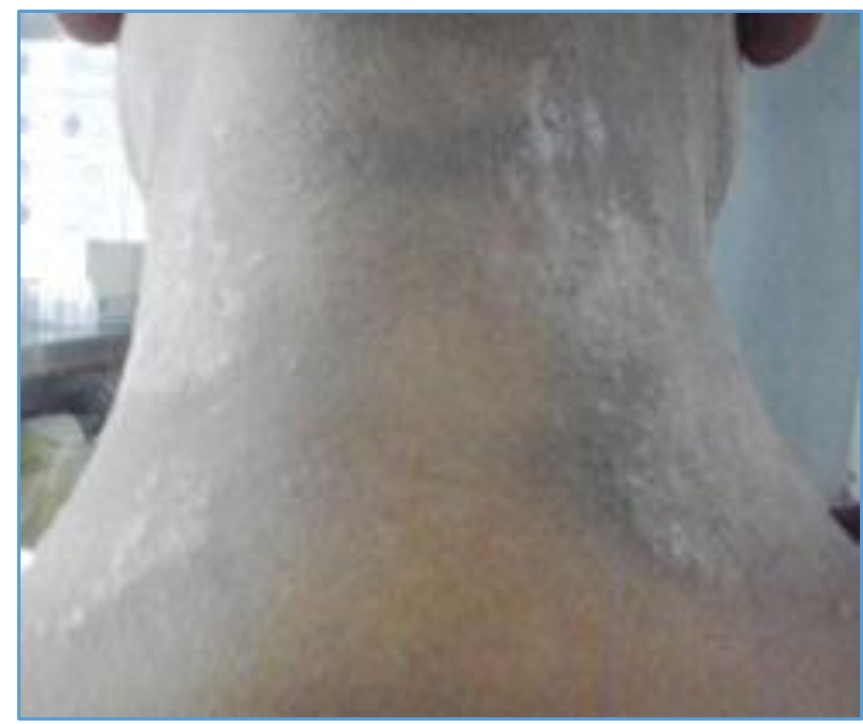

Fig. 2: T. corporis

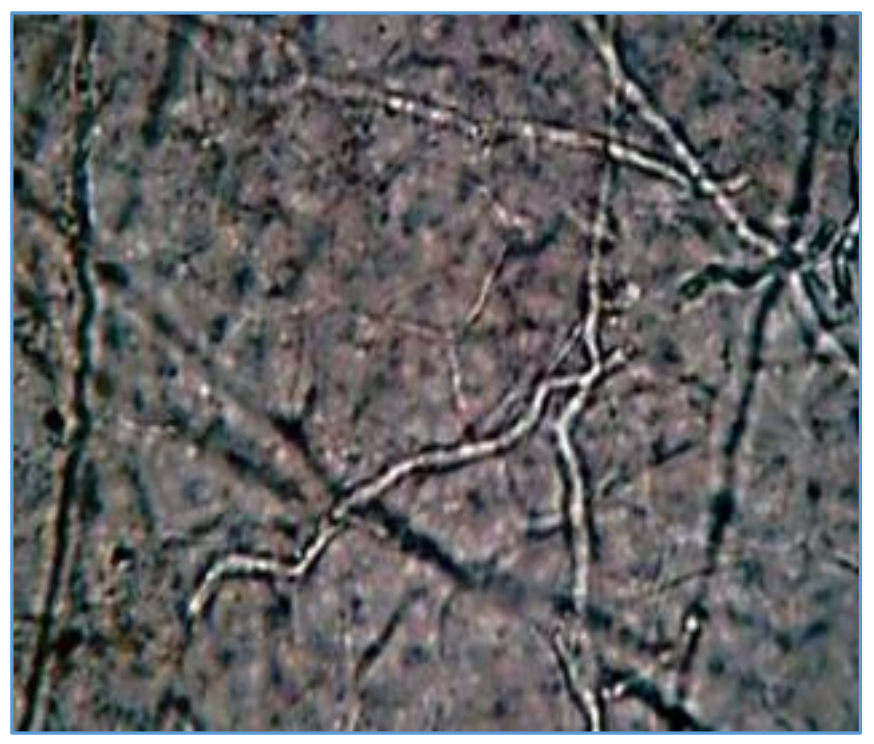

Fig. 3: KOH Mount showing Branching, Hyaline, Septate Hyphae

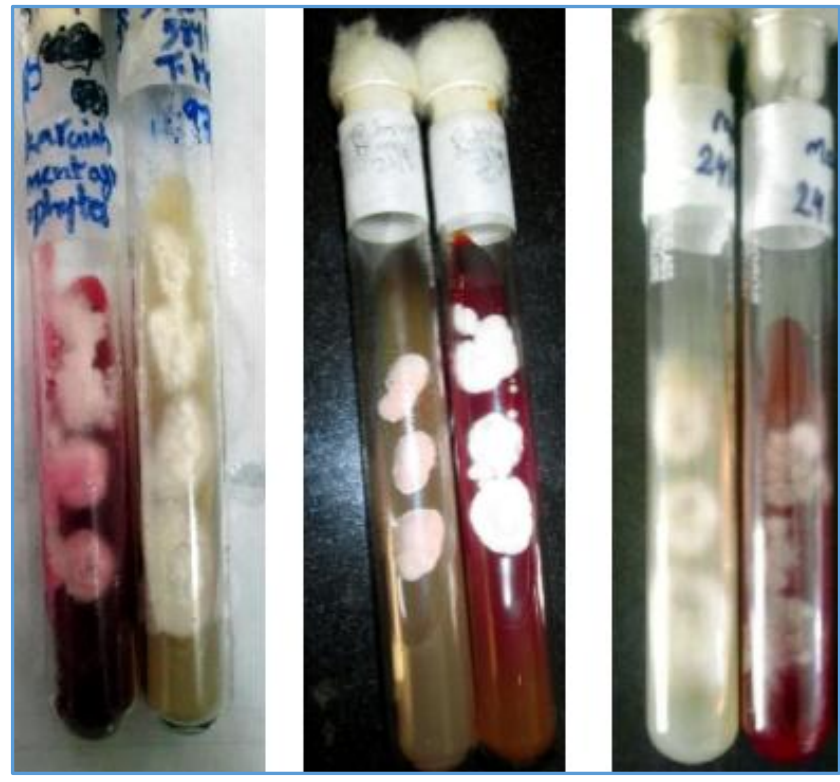

Fig. 4: Culture of T. rubrum, T. mentagrophyte \& E. flocossum

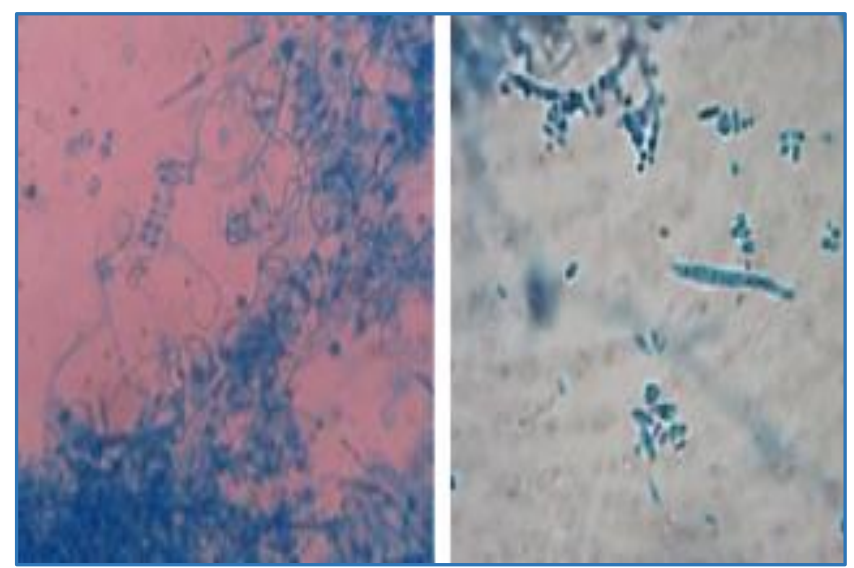

Fig. 5: LPCB Mount showing Spiral Hyphae and Conidia of T. mentagrophyte

\section{DISCUSSION}

Dermatophytosis is one of the most common fungal infections widely distributed throughout the world with increasing frequencies in tropical and sub-tropical countries. In present study, majority of the patients were males $65(73.86 \%)$ and females contributed only $23(26.13 \%)$ of total cases and majority of the patients were the age group of 21-40 years (48.86\%) followed by $41-60$ years (26.13\%), then below 20 years $(22.72 \%)$ and only $2(\%)$ patients were above 60 years of age. This correlates well with the studies conducted by Bhatia et al ${ }^{11}$, Omar B J et $\mathrm{al}^{12}$ and Nawal et $\mathrm{al}^{13}$ The KOH positivity was observed in $58(65.90 \%)$ patients and culture positivity was observed in $59(67.04 \%)$ of total specimens. This finding explains that the culture sensitivity was slightly higher than the $\mathrm{KOH}$ in identifying the causative agent.

These findings correlate with the studies done by Omar B J et al ${ }^{12}$, Fathi $\mathrm{H}$ I et $\mathrm{al}^{14}$ and Sumathi et al15, where the culture positivity was slightly higher than $\mathrm{KOH}$ positivity ( $49 \%$ and $55 \% ; 45 \%$ and $51.4 \% ; 45 \%$ and $50 \%$ respectively). In contrast Mathur $\mathrm{M}$ et al ${ }^{16}$, Richa Sharma et al ${ }^{17}$ and Neetu J $\mathrm{N}$ et al ${ }^{18}$ observed higher KOH positivity when compared to culture (KOH and culture: $71.5 \%$ and $62 \%, 85 \%$ and $60 \%$, $72.5 \%$ and $58.33 \%$ respectively). 
In a recent study conducted by Surendran et al. KOH.19 positivity was quite high with $96 \%$ were positive by $\mathrm{KOH}$, whereas only $39 \%$ were culture positive with only 4 cases of culture positivity observed in $\mathrm{KOH}$ negative samples.

\begin{tabular}{|c|c|c|c|c|}
\hline & $\begin{array}{c}\text { Hanumanthappa } \\
\text { et al. } \\
\text { (2012).20 }\end{array}$ & $\begin{array}{c}\text { Kamothi } \\
\text { et al. } \\
\text { (2010).21 }\end{array}$ & $\begin{array}{c}\text { Nawal } \\
\text { et al. } \\
\text { (2012).13 }\end{array}$ & $\begin{array}{c}\text { Present } \\
\text { Study }\end{array}$ \\
\hline $\begin{array}{c}\text { KOH +ve, } \\
\text { culture } \\
\text { +ve }\end{array}$ & $36 \%$ & $65.21 \%$ & $55.08 \%$ & $55.68 \%$ \\
\hline $\begin{array}{c}\text { KOH +ve, } \\
\text { culture } \\
\text {-ve }\end{array}$ & $30.6 \%$ & $34.72 \%$ & $17.36 \%$ & $10.22 \%$ \\
\hline $\begin{array}{c}\text { KOH -ve, } \\
\text { culture } \\
\text { +ve }\end{array}$ & $12.6 \%$ & $11.29 \%$ & $7.78 \%$ & $11.36 \%$ \\
\hline $\begin{array}{c}\text { KOH -ve, } \\
\text { culture } \\
\text {-ve }\end{array}$ & $20.6 \%$ & $88.77 \%$ & $19.76 \%$ & $22.72 \%$ \\
\hline \multicolumn{5}{|c|}{ Table 5: Comparative Evaluation of KOH and } \\
\multicolumn{5}{|c|}{ Culture Positivity in Various Studies } \\
\hline
\end{tabular}

In our study, the commonest clinical type was $\mathrm{T}$. corporis accounting to $32(36.36 \%)$ out of 88 specimens. The second most common clinical type in our study was T. cruris contributing $22.72 \%$ followed by $\mathrm{T}$. capitis contributing to $9.09 \%$ of total isolates. Mixed (Multiple) site infections were also commonly encountered in our study accounting to $17.04 \%$. These finding correlates with the Hanumanthappa et $\mathrm{al}^{20}$, Kamothi et al21, Nawal et $\mathrm{al}^{13}$ and Mathur $\mathrm{M}$ et al. The other clinical types, which occurred less frequently in our study were T. pedis (5.68\%), T. unguium (4.54\%) and T. faciei $(3.40 \%)$ and T. barbae (1.13\%). ${ }^{16}$ In Surendran et al ${ }^{19}$ study Tinea corporis (44.3\%) was the most common clinical pattern observed followed by tinea cruris (38.2\%), tinea pedis $(2.7 \%)$, tinea manuum $(3.3 \%)$, tinea unguium $(8.1 \%)$, tinea barbae $(2.1 \%)$, and tinea faciei $(1.3 \%)$. In the present study majority of the isolates belonged to the genera Trichophyton 53 (89.8\%), followed by Microsporum 5 (8.47\%) and only single case of Epidermophyton floccosum was $1.69 \%$ isolated.

In the Trichophyton genus, the predominant species isolated was T. mentagrophytes, accounting to 41 (69.5\%) of the total isolates followed by T. rubrum 9 (15.25\%). This finding correlates well with the study conducted by Adefemi SA et al.22 where the predominant isolate was T. mentagrophytes $73.3 \%$.

In contrast to our study, majority of the studies conducted in India and elsewhere have shown T. rubrum as the predominant isolate followed by $\mathrm{T}$. mentagrophytes as the second common isolate. The isolation rate of $\mathrm{T}$. mentagrophytes was ranging from $13.4 \%$ to $31 \%$. Kamothi, M. N. et al. ${ }^{20} 13.4 \%$, Nawal et al. ${ }^{13} 14.1 \%$, Nidhi Prasad et al. ${ }^{22}$ 21.4\%, Madhavi S et al. ${ }^{6} 31 \%$. In Surendran et al. study, Trichophyton rubrum (67.5\%) was the highest followed by Trichophyton mentagrophytes (20\%).

All the remaining Trichophyton species contributed only a minor part accounting to only $5 \%$ of total isolates, which include T. verrucosum $1.69 \%$ and $\mathrm{T}$. tonsurans $3.39 \%$.

Next to the Trichophyton genus, the second most common genus isolated in our study was Microsporum contributing to $5(8.47 \%)$ of the total isolates. All the 5 isolates were identified as M. canis. Studies conducted by Nidhi Prasad et al23, Surendran et al ${ }^{19}$ and Ibrahim et al ${ }^{11}$ has showed the M. canis isolation rate of $0.87 \%, 2.5 \%$ and $17.8 \%$ respectively. Our findings are similar to the above mentioned studies.

The least common isolate in our study was Epidermophyton floccosum accounting to only 1 (1.69\%). Our findings correlate well with the findings of Hanumanthappa et al.19, where E. floccosum was the least common isolate contributing $0.7 \%$.

Mahbubnagar, the least developed district in the entire Telangana has a diverse group of people with majority of them living in the substandard conditions with poor hygienic practices. The dermatophyte infections are often neglected by many of them as they are not life-threatening and are presented to the hospital only in severe cases with extensive lesions. And also a constant change in the epidemiological and aetiological patterns can be expected in such a diverse cultural, habitual and economically variable population. Identifying the changing epidemiological patterns are always important in the appropriate management of the patients.

\section{CONCLUSION}

The present study identifies $\mathrm{T}$. mentagrophytes as the principal aetiological agent in and around Mahbubnagar surpassing $\mathrm{T}$. rubrum, which is the most common agent isolated in major parts of India. This variation in the epidemiological pattern may be associated with environmental factors, local cultural and habitual variants with respect to a particular geographical area, which may change from time to time.

\section{REFERENCES}

1. Weitzman, Summerbell RC. The dermatohytes. clinical midrobial rev 1995;8(2):240-59.

2. Emmon's CW, Bindford $\mathrm{CH}$, Utz IP, et al. Dermatophytosis. Medical mycology. Lea \& Febiger: Philadelphia 1977;3(10):117-673.

3. Niranjan HP, Padmaja N, Priyanka BV. Study of onychomycosis at a tertiary care hospital in South India. J Evol Med Dent Sci 2012;1(5):823-9.

4. Venkatesan G, Singh AJA, Murugesan AG, et al. Trichophyton rubrum-the predominant aetiological agent in human dermatophytosis in Chennai, India. Afr J Microbiol Res 2007;1(1):9-12.

5. Pandey A, Pandey M. Isolation and characterization of dermatophytes with tinea infection at gwalior (mp), India. Int J Pharm Sci Investig 2013;2(2):05-08.

6. Madhavi S, Rama Rao MV, Jyothsna K. Mycological study of dermatophytosis in rural population. Annals of Biological Research 2011;2(3):88-93.

7. Maruthi YA, Hossain K, Chaitanya DA. Incidence of dermatophytes school soils of visakhapatnam: a case study. Asian J Plant Sci Res 2012;2(4):534-8.

8. Reddy KN, Srikanth BA, Sharan TR, et al. Epidemiological, clinical and cultural study of onycomycosis. Am J Dermatol Venereol 2012;1(3):3540.

9. Cheesbrough M. District laboratory practice in tropical countries. Cambridge university presss 2012; Vol II:2347. 
10. Jagdish Chander. Text book of medical mycology. Dermatophytosis, 1999;3rd edn:122-47.

11. Bhatia VK, Sharma PC. Epidemiological studies on dermatophytosis in human patients in Himachal Pradesh, India. SpringerPlus 2014;3:134.

12. Omar BJ, Agnihotri P, Pande RC, et al. Non dermatophytic fungal infections amongst dermatophytosis- a hospital based study. Indian Journal of Community Health 2013;25(1).

13. Pradeep Nawal, Sachin Patel, Mitesh Patel, et al. A study of superficial mycoses in tertiary care hospital. NJIRM 2012;3(1):90-93. eISSN: 0975-9840, pISsN: 2230-9969.

14. Fathi HI, Samarai AMAI. Tinea capitis in Iraq: laboratory results. La Revue de Sante de la Mediterra-nceorientale 2000;6(1):138-48.

15. Sumathi, Mariraj J, Shafiyabi S, et al. Clinicomycological study of dermatophytes. Int J Pharm Biomed Res 2013;4(2):132-4.

16. Mathur M, Kedia SK, Ghimire RBK. Epizoonosis of dermatophytosis: a clinico-mycological study of dermatophytic infections in central Nepal. Kathmandu Univ Med J 2012;37(1):30-3.

17. Richa Sharma, Nakuleshwar Dut Jasuja, Suresh Sharma. Clinical and mycological study of dermatophytosis in Jaipur (India). International Journal of Pharmacy and Pharmaceutical Sciences 2012;4(3):215-7. ISSN-09751491.
18. Neetu Jain, Meenakshi Sharma, Saxena VN. Clinicomycological profile of dermatophtosis in Jaipur, Rajasthan. Indian J Dermatol Venereol Leprol 2008;74(3):274-5.

19. Surendran KAK, Ramesh M Bhat, Rekha Boloor, et al. A clinical and mycological study of dermatophytic infections. Indian J Dermatol 2014;59(3):262-7.

20. Hanumanthappa H, Sarojini K, Shilpashree P, et al. Clinicomycological study of 150 cases of dermatophytosis in a tertiary care hospital in South India. Indian J Dermatol 2012;57(4):322-3.

21. Kamothi MN, Patel BP, Mehta SJ, et al. Prevalence of dermatophyte infection in district Rajkot. Electronic Journal of Pharmocology and Therapy 2010;3:1-3.

22. Adefemi SA, Odeigah LO, Alabi KM. Prevalence of dermatophytosis among primary school children in okeoyi community of Kwara state. Niger J Clin Pract 2011;14(1):23-8.

23. Nidhi Prasad, Mahapatra A, Chayani N. Changing trends in the fungal isolates from clinical specimens of suspected superficial mycosis. Indian Medical Gazette 2013. 